\title{
CORRIGENDA
}

\section{Identification of potential biomarkers of exposure to di(isononyl)cyclohexane-1,2-dicarboxylate (DINCH), an alternative for phthalate plasticizers}

Manori J. Silva, Johnathan Furr, James L. Preau Jr, Ella Samandar, L. Earl Gray and Antonia M. Calafat

Journal of Exposure Science and Environmental Epidemiology (2012) 22, 427; doi:10.1038/jes.2012.16

Correction to: Journal of Exposure Science and Environmental Epidemiology (2012) 22, 204-211; doi:10.1038/jes.2011.43; published online 18 January 2012
In this article, there is an error in the abstract, lines 5 and 6 . The sentence should be "We positively identified and accurately quantified CHDA and cyclohexane-1,2-dicarboxylic acid, mono hydroxyisononyl ester (MHNCH) using authentic standards."

\section{Comparative international analysis of radiofrequency exposure surveys of mobile communication radio base stations}

Jack T. Rowley and Ken H. Joyner

Journal of Exposure Science and Environmental Epidemiology (2012) 22, 427; doi:10.1038/jes.2012.17

Correction to: Journal of Exposure Science and Environmental Epidemiology advance online publication, 29 February 2012; doi:10.1038/jes.2012.13

In this article, there are two errors. On page 3, left column, RESULTS section, second paragraph, second sentence, the sentence should be "We calculated a global average across all measurements, weighted by the number of points per country, as $0.073 \mu \mathrm{W} / \mathrm{cm}^{2}$ as indicated by the lower dotted line in Figure 1."
On page 8 , left column, the second sentence under Mobile networks comply with RF exposure limits should be "The global average in Figure 1 at $0.073 \mu \mathrm{W} / \mathrm{cm}^{2}$ is more than nearly 5500 times below the most restrictive ICNIRP reference level for the public relevant to these mobile communication services $\left(400 \mu \mathrm{W} / \mathrm{cm}^{2}\right.$ at $800 \mathrm{MHz}$ )." 